\title{
Screening of Citric Acid Producing Fungi from the Leaf Litter Soil of Sathuragiri Hills
}

\author{
Thiruvengadam Shankar*, Thangavel Sivakumar
}

Department of Microbiology, Ayya Nadar Janaki Ammal College (Autonomous), India

Copyright $\bigcirc 2016$ by authors, all rights reserved. Authors agree that this article remains permanently open access under the terms of the Creative Commons Attribution License 4.0 International License

\begin{abstract}
Soil samples were collected from ten different locations of Sathuragiri Hills (Western Ghats, Tamilnadu). Percentage frequency of occurrence of fungal isolates was calculated. Cultural characteristics of fungal isolates on Sabouraud's dextrose agar were observed. Fungal isolates were identified based on morphology, cultural characteristics and $18 \mathrm{~S}$ rRNA sequencing. Citric acid production ability of fungal isolates was screened. Among the isolates Aspergillus niger found to produce the highest quantity of citric acid (2.5 $\pm 0.01 \mathrm{~g} / \mathrm{L}$ ) and it is selected for further work.
\end{abstract}

Keywords Screening, Citric Acid, Fungi, Leaf Litter, Pharmaceutical

\section{Introduction}

Citric acid $\left(\mathrm{C}_{6} \mathrm{H}_{8} \mathrm{O}_{7}, \quad\right.$ 2-hydroxy-1,2,3-propane tricarboxylic acid), a natural constituent and common metabolite of plants and animals, is the most versatile and widely used organic acid in the field of food $(70 \%)$ and pharmaceuticals $(12 \%)$. It has got several other applications in various other fields. Currently, the global production of citric acid is estimated to be around 736000 tones/year [1] and the entire production is carried out by fermentation. There is constant increase (3.5-4\%) each year in its consumption, showing the need of finding new alternatives for its manufacture [2].

Citric acid is an intermediate of tricarboxylic acid (TCA) cycle which is obtained when carbohydrates are oxidized to carbon dioxide. It has three carboxylic acid functional groups with three $\mathrm{pKa}$ values at $\mathrm{pH} 3.1,4.7$ and 6.4. It is a ubiquitous intermediate product of metabolism and its traces are found virtually in all plants and animals [3].

Citric acid is known as the most important organic acid produced in tonnage by fermentation and is the most exploited biochemical/biotechnological product [4]. It has an annual production of 1.6 million tons [5] with annual growth demand /consumption rate of 3.5-4.0\% [6].

Citric acid is responsible for the tart taste of various fruits in which it occurs (i.e. lemons, limes, figs, oranges, pears and goose-berries). Hence, citric acid is used to impart a pleasant tart flavours to foods and beverages. It is used in the industries to achieve acidulation, antioxidation, emulsification, preservation, flavour enhancement, and as plasticizer and synergistic agent [7]. The wide applicability of citric acid in industries is attributed to its low/non-toxicity, high solubility; biodegradability and palatability [8].

It is a product adjudged to be GRAS (Generally Recognized as Safe). The food industry consumes about $70 \%$ of total citric acid produced and pharmaceutical industries consume about $12 \%$ and the remaining $18 \%$ are consumed by other industries [6]. The demand for citric acid is increasing faster than its production and hence, more economical processes are required [9].

The supply of natural citric acid is very limited and the demand can only be satisfied by biotechnological processes [10]. Many microorganisms such as fungi, bacteria and yeast can produce citric acid. A large number of these microorganisms have been employed for citric acid production, but only a few of them can produce citric acid in industrial scale [7]. It is reported that Aspergillus niger is almost exclusively used for industrial scale production of citric acid. This is due to its high citric acid productivity at low $\mathrm{pH}$, without secretion of toxic metabolites, ease of handling and ability to ferment a variety of cheap raw materials. Citric acid is commercially produced by large scale fermentation mostly using selected fungal or yeast strains in aerobe bioreactors [10].

A large number of microorganisms including fungi and bacteria such as Arthrobacter paraffinens, Bacillus licheniformis and Corynebacterium sp., Aspergillus niger, A. aculeatus, A. carbonarius, A. awamori, A. foetidus, A. fonsecaeus, A. phoenicis and Penicillium janthinellum; and yeasts such as Candida tropicalis, C. oleophila, $C$. guilliermondii, C. citroformans, Hansenula anamola and Yarrowia lipolytica have been employed for citric acid production [11]. Most of them, however, are not able to produce commercially acceptable yields due to the fact that citric acid is a metabolite of energy metabolism and its 
accumulation rises in appreciable amounts only under conditions of drastic imbalances. Among the mentioned strains, the fungus $A$. niger has remained the organism of choice for commercial production because it produces more citric acid per time unit. The problem in the production of citric acid for yeasts is the simultaneous formation of isocitric acid. The main advantages of using $A$. niger are its ease of handling, its ability to ferment a variety of cheap raw materials, and high yields. Industrial strains which produce commercial citric acid are not freely available and only a few can be obtained from international culture collections.

In this context, the isolation and identification of a potential citric acid producing fungal strain from the Western Ghats of Tamilnadu will be attempted in the present investigation considering the fact that novel and potential citric acid producing strain can be isolated from biodiversity niche. This species may be found to be very effective comparatively with the existing microbial strains. Microorganisms in Western Ghats of Tamil Nadu form a potential source for exploring novel microbial products, due to their unique natural habitat, distinct physiological characteristics, metabolic patterns and nutrient utilization.

\section{Materials and Methods}

\subsection{Sampling Area}

The leaf litter soil samples were collected out in Sathuragiri Hills (Western Ghats, Tamilnadu) is about 15
Kms from Srivilliputhur. The town is situated on latitude 9.727288300000001000" North and longitude 77.618638299999930000 " East. The town is about 4500 feet above the sea level.

\section{Sample collection}

Soil samples were collected from ten different locations in leaf litter degrading soil environment of Sathuragiri Hills (Western Ghats, Tamilnadu). Using a sterilized spatula, 250g of soil sample was collected from each location into 300g-capacity plastic container which was previously washed and rinsed with $70 \%$ alcohol. The samples from the ten different sites were conveyed to the Microbiology Laboratory within same day, where they were analyzed.

\subsection{Isolation and Identification of Fungal Isolates}

Serial dilutions of soil samples from each site were prepared and inoculated in duplicates into Sabouraud's Dextrose Agar (SDA) plates by spread plate methods. The plates were incubated at $30^{\circ} \mathrm{C}$ for 3 days and observations were made daily to determine the presence of filamentous fungi. Pure cultures of isolates were obtained by repeated sub-culture on SDA [12].

The fungal isolates were identified based on the basis of their cultural and morphological characteristics. The cultural characteristics were determined by their appearance on culture plates while the morphological features were determined microscopically. The isolates were identified with reference to the work of Domsch et al. [13].

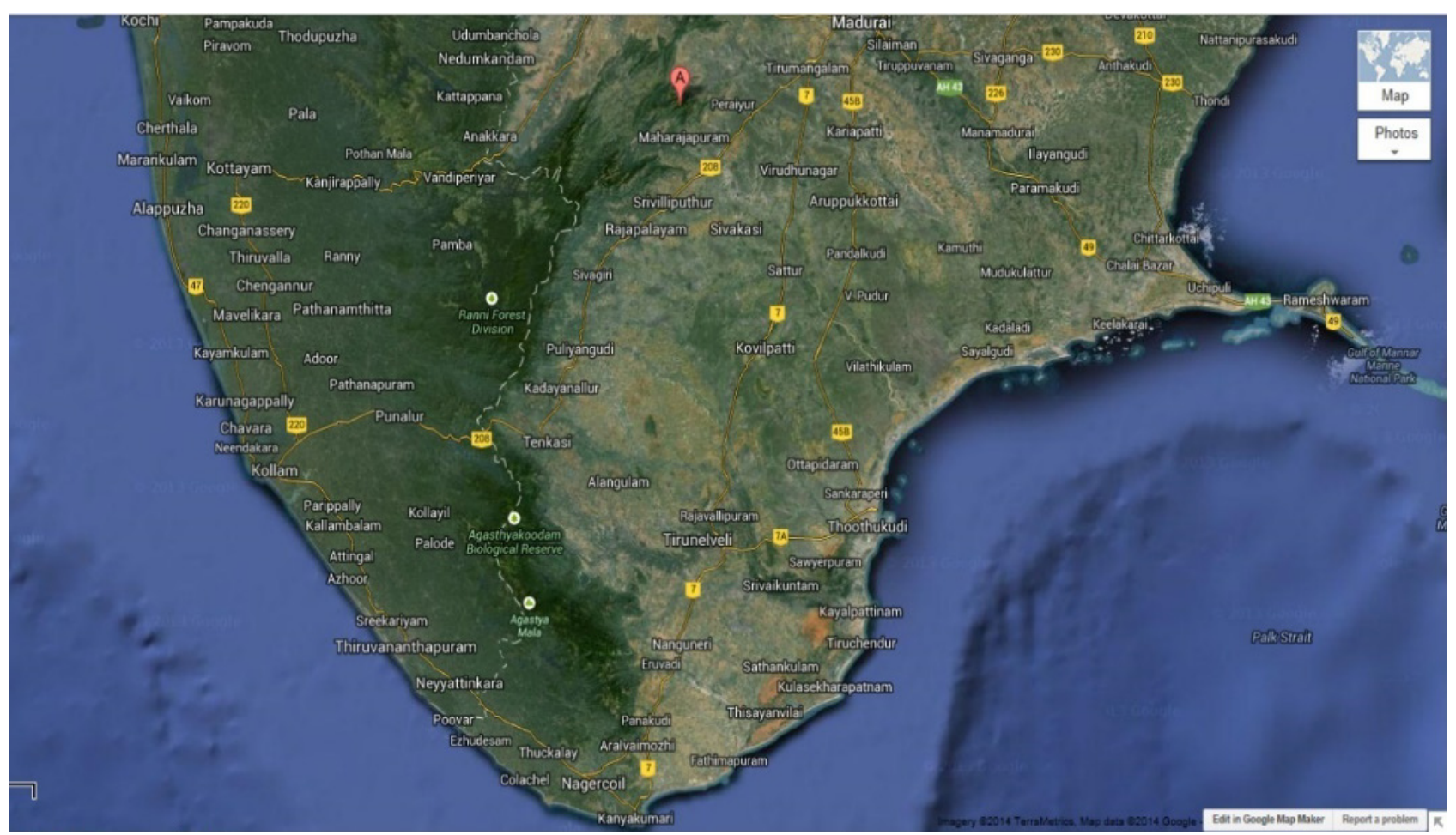

Figure 1. Map shows the sampling site - (Sathuragiri Hills, Western Ghats, Tamilnadu) 


\subsection{Determination of Percentage Frequency of Occurrence of Isolates}

The percentage frequency of occurrence for each species of fungus was determined by the method of using the formula: A/B X 100; where, $A=$ Number of plates in which species appear and $\mathrm{B}=$ Total number of plates incubated for each sites [14].

\subsection{Citric Acid Production Medium}

Strains were screened for citric acid production in liquid culture which contained sucrose $(\mathrm{g} / \mathrm{l}) 120 \mathrm{~g} ; \mathrm{NaNO}_{3}-5 \mathrm{~g}$; $\mathrm{KH}_{2} \mathrm{PO}_{4}-2 \mathrm{~g} ; \quad \mathrm{MgSO}_{4} .7 \mathrm{H}_{2} \mathrm{O}-1 \mathrm{~g} ; \quad \mathrm{CuSO}_{4} .7 \mathrm{H}_{2} \mathrm{O}-0.02 \mathrm{~g}$; $\mathrm{FeSO}_{4} \cdot 7 \mathrm{H}_{2} \mathrm{O}-1 \mathrm{~g}$ and $\mathrm{ZnSO}_{4} .7 \mathrm{H}_{2} \mathrm{O}-1 \mathrm{~g}$ in distilled water $-1000 \mathrm{ml}$. The $\mathrm{pH}$ of medium was adjusted to 6 [15].

\subsection{Selection of Strain for Citric Acid Production}

Based on the colony morphology the fungal isolates were designated as AS1, AS2, AS3, AS4, AS5, AS6 and AS7. These strains were inoculated individually in the production broth and incubated at $37^{\circ} \mathrm{C}$ for 3 days and then they were analyzed for the citric acid production.

\subsection{Isolation and Identification of Fungal Strains}

The isolated colonies AS1, AS2, AS3, AS4, AS5, AS6 and AS7 were examined by lactophenol cotton blue technique and identified according to their morphological characteristics [16]

\subsection{Screening of the Fungal Cultures}

All the seven cultures were screened qualitatively for the production of citric acid as described by Ali, [17]. Czapek-Dox agar medium $(20 \mathrm{~mL})$ was poured into individual sterile Petri plates and allowed to cool at room temperature. The plates were incubated at $30^{\circ} \mathrm{C}$ for $3-5$ days. The plates were observed after incubation for yellow zones due to citric acid formation. Strains of Aspergillus niger with the widest yellow zone were used for further studies.

\subsection{Determination of Citric Acid Production by Fungal Isolates}

Czapek-Dox broth $(50 \mathrm{~mL})$ was prepared in seven conical flasks and sterilized. They were allowed to cool at room temperature. The conical flasks were inoculated with seven different fungal isolates and incubated at $30^{\circ} \mathrm{C}$ for $3-5$ days. The broth was centrifuged at 5000rpm for 10 minutes and the supernatant was taken for citric acid estimation. Citric acid was determined titrimetrically [18] by using $0.1 \mathrm{NaOH}$ and phenolphthalein as indicator and calculated as \% according to the formula:

$\% \mathrm{CA}=$ Normality $\times$ volume of $\mathrm{NaOH} \times$ Equiv. wt. of $\mathrm{CA} /$ Weight of sample $\times 10$

\section{Results}

The results of the soil samples of the different locations in Sathuragiri Hills (Western Ghats, Tamilnadu) are presented here. While Table 1 shows the results of the Total Fungal Counts in the soil samples of the different locations. The percentage frequencies of occurrence of fungal isolates are presented in Table 2, while the results of the cultural characteristics of isolates are presented in Table 3. The results of the citric acid levels produced by the fungal isolates are presented in Table 4.

Sri Santhana Mariamman, Thavasipaarai and Periyapasukidai had high fungal counts of $2.4 \times 10^{4}, 2.2 \times 10^{4}$ and $2.1 \times 10^{4}$ respectively. Also, Thaniparai entrance and Nadu kali had counts of $1.9 \times 10^{4}, 1.8 \times 10^{4}$ respectively. Also, by this Pacharisi-Paarai and Pala-AdiKaruppar Swamy had a similar count's of $1.6 \times 10^{4}$ respectively. Whereas, Chinnapasu-kidai sampling area had the least amount of fungal count of about $1.2 \times 10^{4}$ (Table 1 ).

Table 1. Total Fungal Count (TFC/g) of Soil Samples from Different Location of Sathuragiri Hills (Western Ghats, Tamilnadu)

\begin{tabular}{|c|c|}
\hline Sites & TFC/g \\
\hline A & $1.9 \times 10^{4} \pm 0.3$ \\
\hline B & $1.2 \times 10^{4} \pm 0.2$ \\
\hline C & $1.4 \times 10^{4} \pm 0.7$ \\
\hline D & $2.4 \times 10^{4} \pm 0.4$ \\
\hline E & $1.6 \times 10^{4} \pm 0.5$ \\
\hline F & $1.3 \times 10^{4} \pm 0.6$ \\
\hline G & $2.1 \times 10^{4} \pm 0.1$ \\
\hline H & $1.6 \times 10^{4} \pm 0.2$ \\
\hline I & $1.8 \times 10^{4} \pm 0.3$ \\
\hline J & $2.2 \times 10^{4} \pm 0.5$ \\
\hline
\end{tabular}

KEY:

$\mathrm{A}=$ Thaniparai entrance; $\mathrm{B}=$ Chinnapasu-kidai; $\mathrm{C}=$ Naaval Ootru; $\mathrm{D}=\mathbf{S r i}$ Santhana Mariamman; $\mathrm{E}=$ Pacharisi-Paarai; $\mathrm{F}=$ Vana-Durgai Amman; $\mathrm{G}=$ Periyapasukidai; H=Pala-AdiKaruppar Swamy; I=Nadu kali; $\mathrm{J}=$ Thavasipaarai.

Aspergillus sp. had the highest percentage frequency of occurrence of $80 \%$, followed by Aspergillus flavus which had $70 \%$ Cladosporium sp. \& Helminthosporium sp had 40 \& $30 \%$ frequency of occurrence respectively. While, Curvularia sp had a lowest frequency of occurrence about $10 \%$ (Table 2). 
Table 2. Percentage frequency of occurrence of fungal isolates

\begin{tabular}{|c|c|c|c|c|c|c|c|c|c|c|c|}
\hline \multirow{2}{*}{ Fungal Isolates } & \multicolumn{10}{|c|}{ Sites } & \multirow{2}{*}{ Occurrence percentage } \\
\hline & A & B & $\mathrm{C}$ & $\mathrm{D}$ & $\mathrm{E}$ & $\mathrm{F}$ & $\mathrm{G}$ & $\mathrm{H}$ & I & $\mathrm{J}$ & \\
\hline Aspergillus niger & + & + & - & + & + & - & + & + & + & + & 80 \\
\hline Aspergillus flavus & + & - & + & + & + & - & + & - & + & + & 70 \\
\hline Penicillium sp & + & + & - & + & - & + & - & + & - & - & 50 \\
\hline Cladosporium sp & + & - & - & + & + & - & - & + & - & - & 40 \\
\hline Helminthosporium sp & + & - & - & - & + & + & - & - & - & - & 30 \\
\hline Alternaria $\mathrm{sp}$ & - & - & + & - & - & - & + & - & - & - & 20 \\
\hline Curvularia sp & - & - & - & - & - & - & + & - & - & - & 10 \\
\hline
\end{tabular}

Table 3. Cultural characteristics of fungal isolates on Sabouraud's dextrose agar

\begin{tabular}{|c|c|c|}
\hline Isolates & Surface & Reverse \\
\hline Cladosporium sp. & Black & Brownish \\
\hline Aspergillus niger & Greenish-Black & Blackish-White \\
\hline Penicillium sp. & Brownish & Whitish-Red \\
\hline Alternaria sp. & Brownish & Greenish \\
\hline Curvularia sp. & Whitish & Whitish \\
\hline Helminthosporium sp. & Greenish-Black & Brownish \\
\hline Aspergillus flavus & Greenish & Black \\
\hline
\end{tabular}

Aspergillus niger found to produce the highest quantity of citric acid $(2.2 \pm 0.001 \mathrm{~g} / \mathrm{L})$, followed by Aspergillus flavus $(1.32 \pm 0.01 \mathrm{~g} / \mathrm{L})$, Penicillium sp $(1.28 \pm 0.06 \mathrm{~g} / \mathrm{L})$, Helminthosporium sp. $(1.22 \pm 0.02 \mathrm{~g} / \mathrm{L})$. Least amount of citric acid was produced by Cladosporium sp. $(0.92 \pm 0.04$ $\mathrm{g} / \mathrm{L}$ ). These findings have further confirmed the superior of Aspergillus niger as the industrial production species for the citric acid production (Table 4).

Table 4. Citric acid production by fungal isolates.

\begin{tabular}{|c|c|c|}
\hline $\begin{array}{c}\text { Isolates } \\
\text { Numbering }\end{array}$ & Fungal Isolates & $\begin{array}{c}\text { Amount of } \\
\text { Citric Acid }(\mathrm{g} / \mathrm{l})\end{array}$ \\
\hline AS1 & Cladosporium $\mathrm{sp}$. & $0.92 \pm 0.04$ \\
\hline AS2 & Aspergillus niger & $2.20 \pm 0.01$ \\
\hline AS3 & Penicillium sp. & $1.28 \pm 0.06$ \\
\hline AS4 & Alternaria sp. & $1.12 \pm 0.01$ \\
\hline AS5 & Curvularia sp. & $1.14 \pm 0.03$ \\
\hline AS6 & Helminthosporium sp. & $1.22 \pm 0.02$ \\
\hline AS7 & Aspergillus flavus & $1.32 \pm 0.01$ \\
\hline
\end{tabular}

Figure 2b. AS1 = Cladosporium sp. on Sabouraud's Dextrose Agar (SDA) plate 


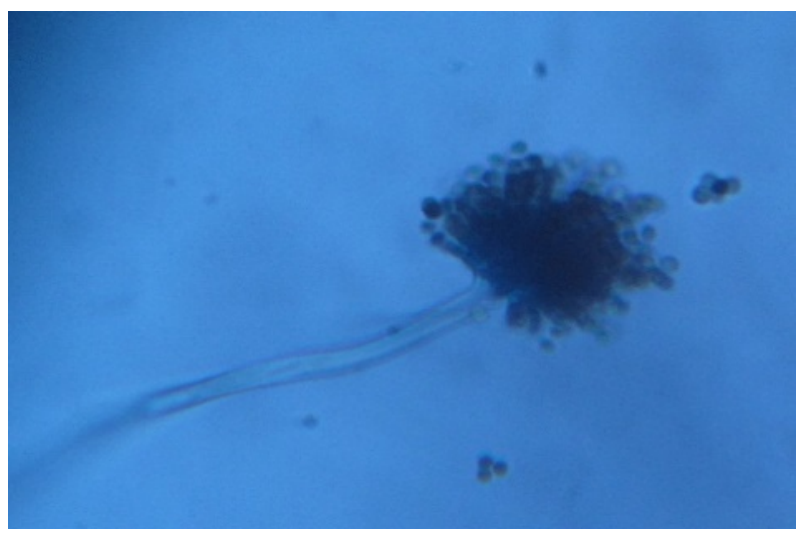

Figure 3a. Lactophenol cotton blue mount of AS2 = Aspergillus niger

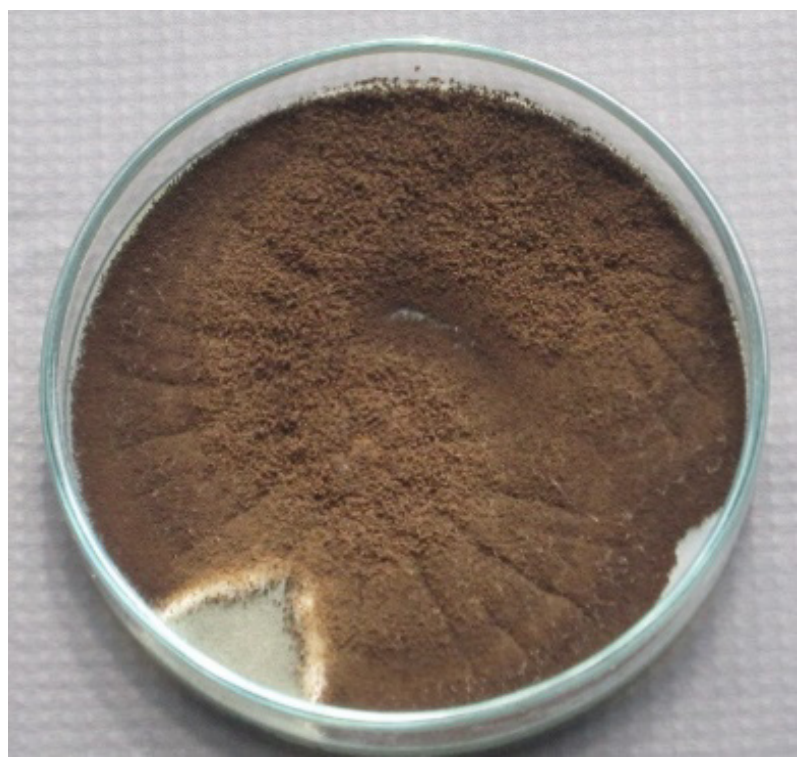

Figure 3b. AS2 = Aspergillus niger on Sabouraud's Dextrose Agar (SDA) plate

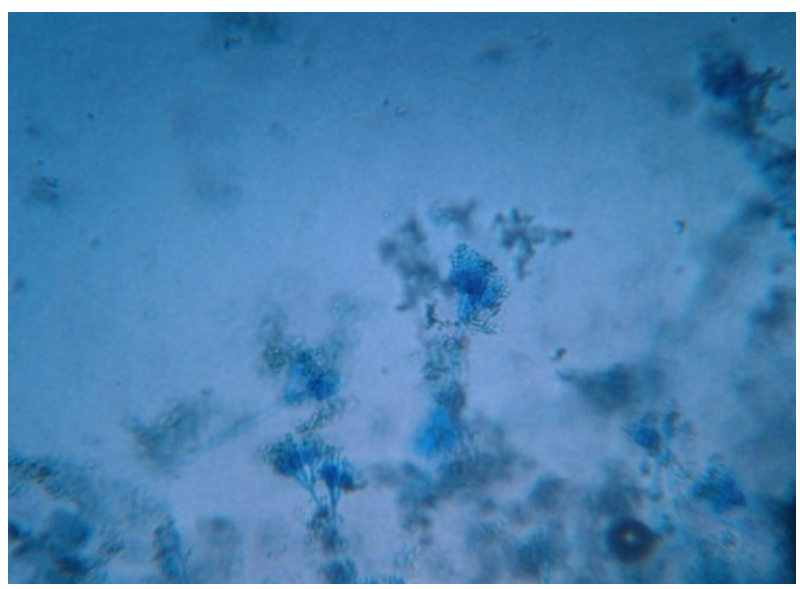

Figure 4a. Lactophenol cotton blue mount of AS3 = Penicillium $\mathrm{sp}$

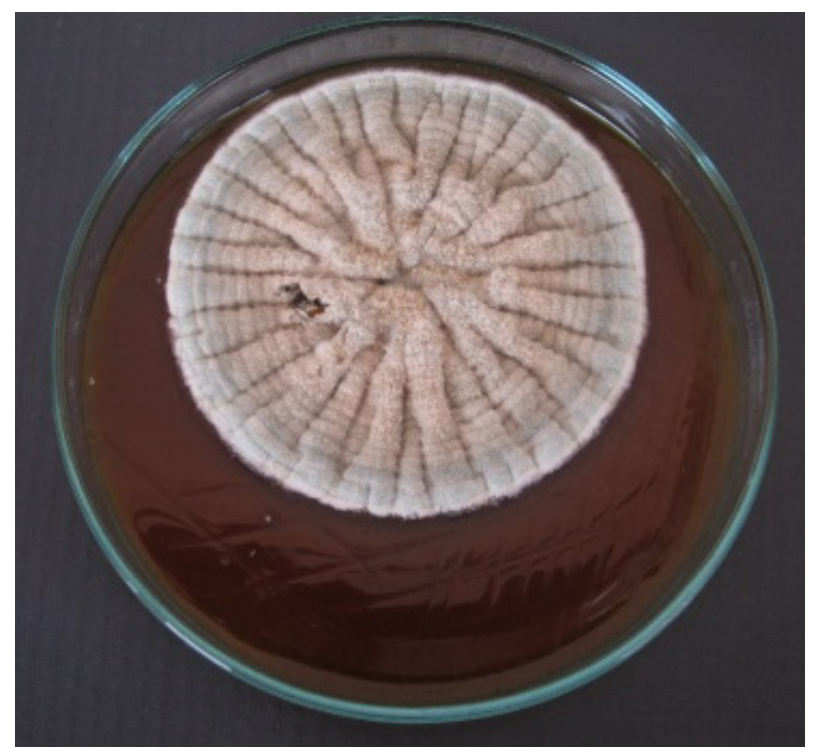

Figure 4b. AS3 = Penicillium sp on Sabouraud's Dextrose Agar (SDA) plate

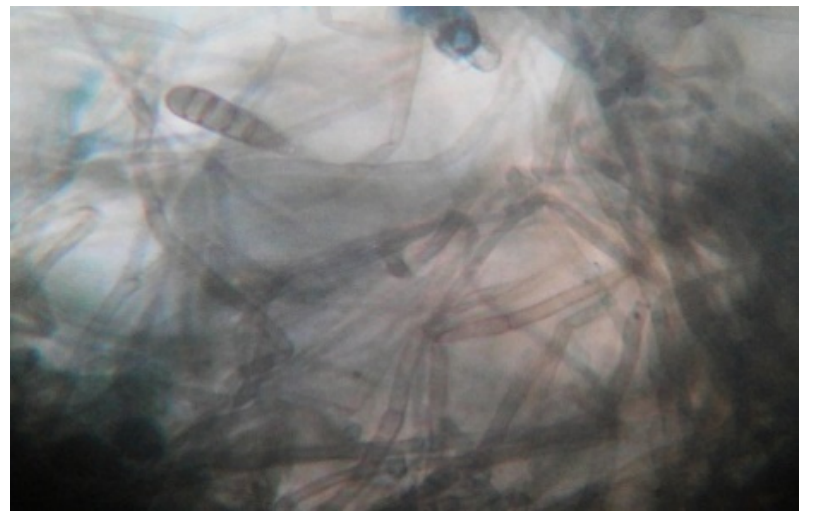

Figure 5a. Lactophenol cotton blue mount of AS4 = Altarnaria sp.

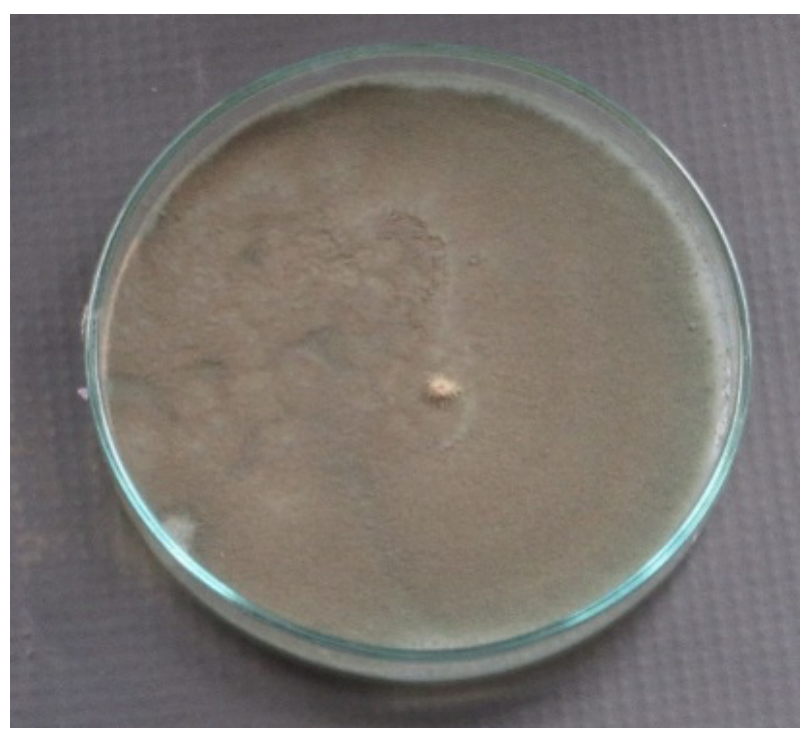

Figure 5b. AS4 = Altarnaria sp. on Sabouraud's Dextrose Agar (SDA) plate 


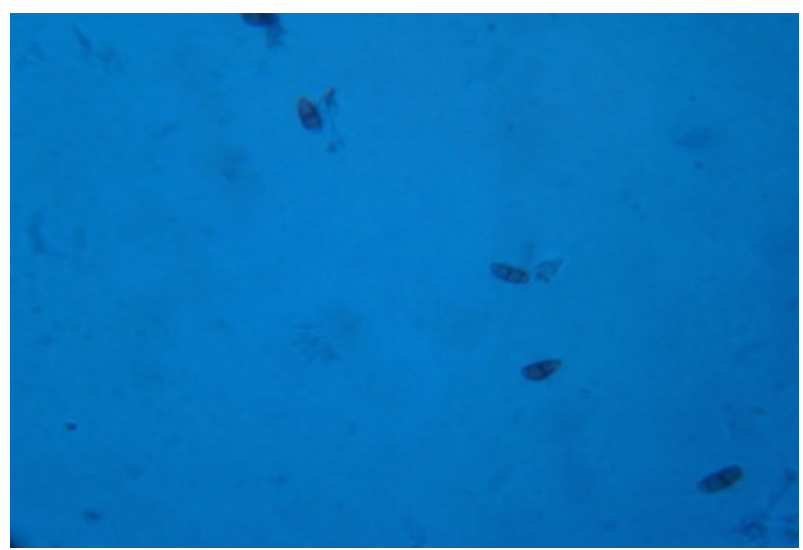

Figure 6a. Lactophenol cotton blue mount of AS5 $=$ Curvularia $\mathrm{sp}$

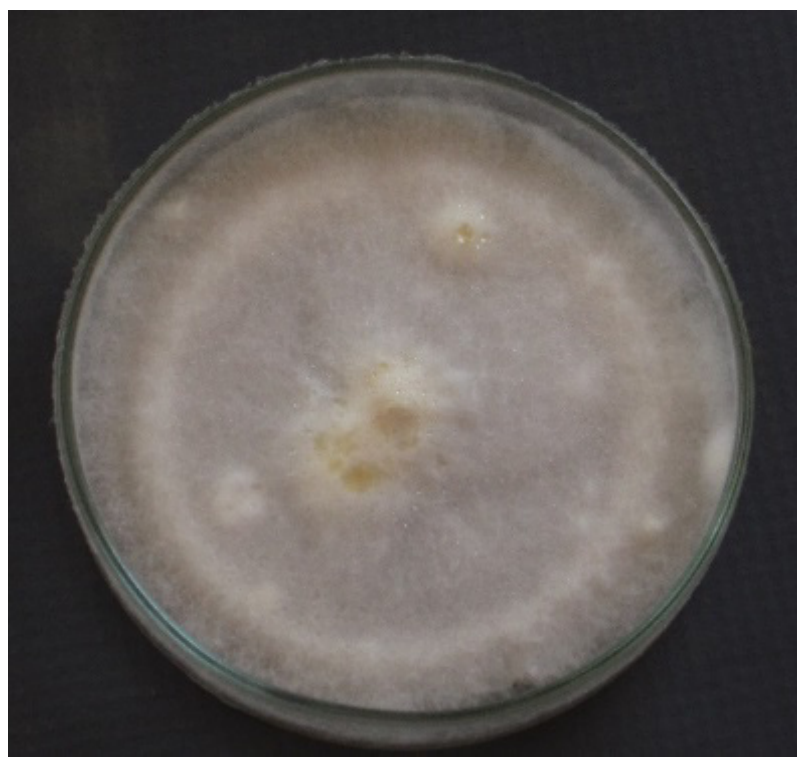

Figure 6b. AS5 = Curvularia sp. on Sabouraud's Dextrose Agar (SDA) plate

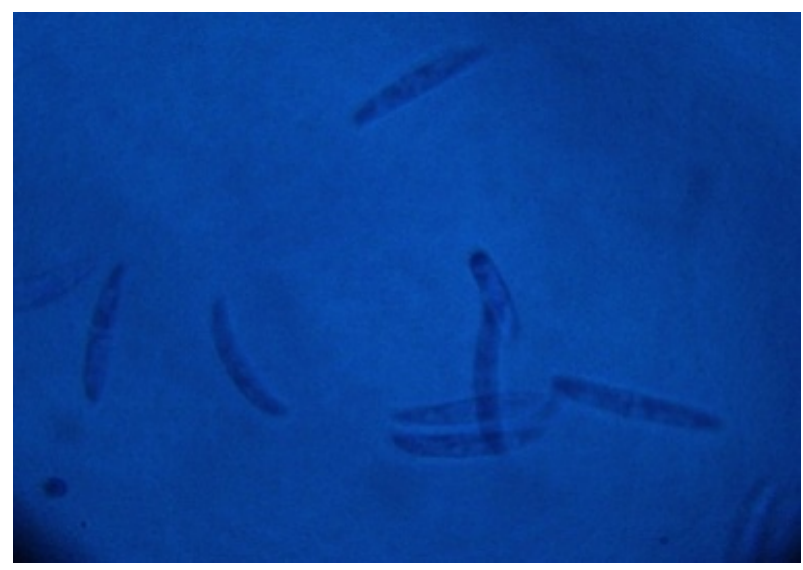

Figure 7a. Lactophenol cotton blue mount of AS6 $=$ Helminthosporium sp.

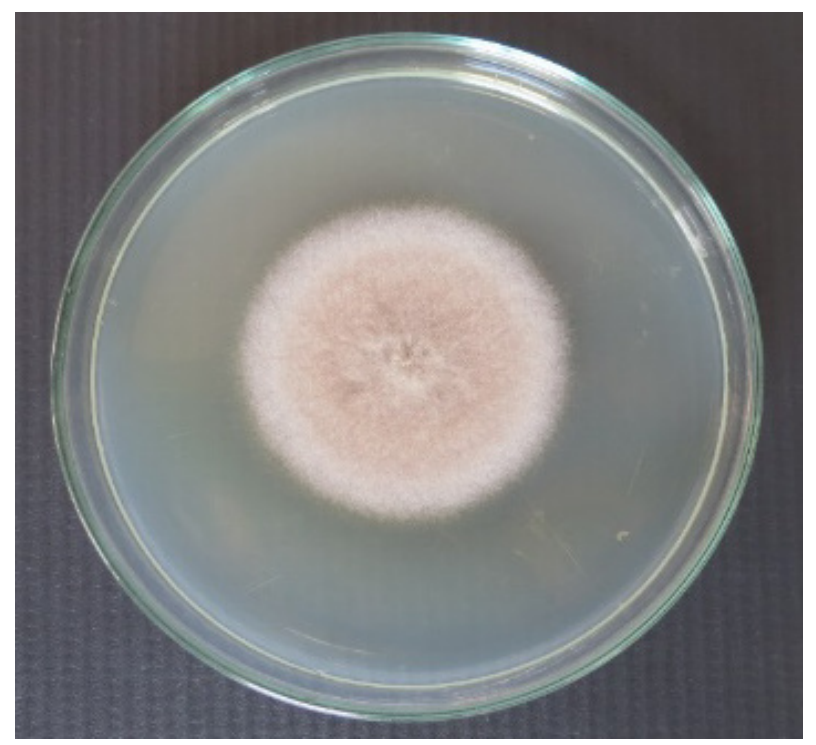

Figure7b. AS6= Helminthosporium sp. on Sabouraud's Dextrose Agar (SDA) plate

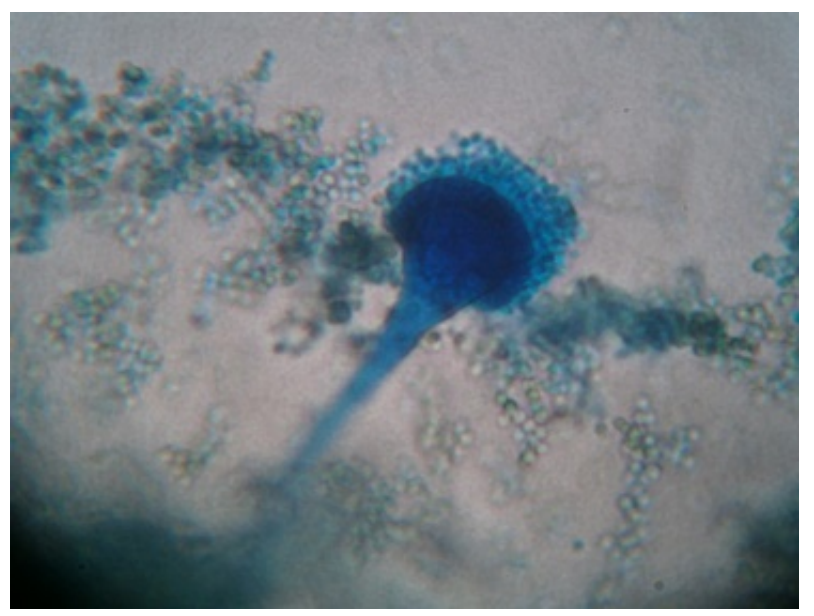

Figure 8a. Lactophenol cotton blue mount of AS7 = Aspergills flavus

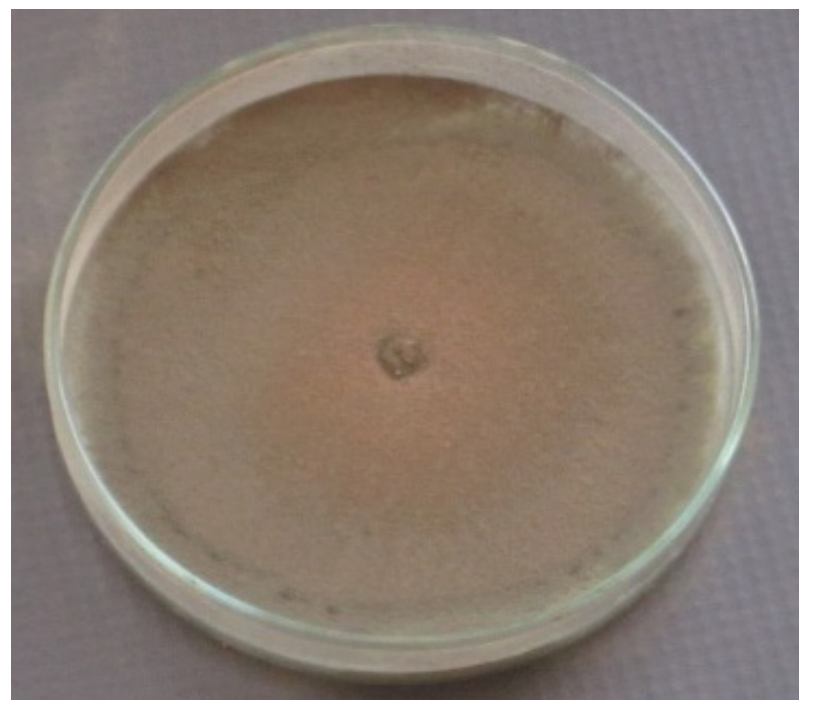

Figure 8b. AS7=Aspergillus flavus on Sabouraud's Dextrose Agar (SDA) plate 


\section{Discussion}

Similarly, in a study carried out in Dadin Kowa, High Court and Angwan Tiv had high fungal counts of $2.1 \times 10^{5}$, $2.5 \times 10^{5}$ and $2.2 \times 10^{5}$ respectively followed by those of the Main Campus and Total Round about which had counts of $1.8 \times 10^{5}$, respectively. Also, Angwan Lambu and Kofar Hausa had counts of $1.5 \times 10^{5}$ while G.R.A and B.C.G had counts of $1.3 \times 10^{5}$ and $1.2 \times 10^{5}$, respectively. Angwan Wuje had the lowest count of $1.0 \times 10^{5}[16]$.

Equally, Aspergillus niger and Penicillium sp had the highest percentage frequency of occurrence of $60 \%$, followed by Rhizopus stolonifer and Trichoderma viride which had 50\%. Aspergillus flavus and Alternaria alternata had $40 \%$ frequency of occurrence respectively. Aspergillus fumigatus had $20 \%$, while Absida corymbifera and Curvularia lunata had the lowest frequency of occurrence of $10 \%[16]$.

Whereas in a study, Aspergillus fumigatus, Cladosporium herbarum, Rhizopus stolonifer, Alternaria alternata and Curvularia lunata did not produce citric acid, while Absida corymbifera, Penicillium sp, Trichoderma viride, Aspergillus flavus and Aspergillus niger produced citric found to produce the highest quantity of citric acid $(8.4 \mu \mathrm{g}$ $\left.\mathrm{ml}^{-1}\right)$, followed by Trichoderma viride $\left(5.1 \mu \mathrm{g} \mathrm{ml}^{-1}\right)$, acid at varying concentrations. Aspergillus niger was A. flavus $(3.2$ $\left.\mu \mathrm{g} \mathrm{ml}{ }^{-1}\right)$, Penicillium sp $\left(2.0 \mu \mathrm{g} \mathrm{ml} l^{-1}\right)$ and Absida corymbifera $\left(1.4 \mu \mathrm{g} \mathrm{ml}^{-1}\right)$, respectively. These findings have further confirmed the superior of Aspergillus niger as the industrial species for the production of citric acid as reported by several workers $[19,20]$. The results also agree with Torres, [21] where it was reported that some species of fungi other than Aspergillus niger also do produce citric acid.

\section{Conclusions}

Aspergillus niger found to produce the highest quantity of citric acid $(2.20 \pm 0.01 \mathrm{~g} / \mathrm{L})$, followed by Aspergillus flavus $(1.32 \pm 0.01 \mathrm{~g} / \mathrm{L})$, Penicillium sp. $(1.28 \pm 0.06 \mathrm{~g} / \mathrm{L})$, Helminthosporium sp. $(1.22 \pm 0.02 \mathrm{~g} / \mathrm{L})$. Least amount of citric acid was produced by Cladosporium sp. (0.92 \pm $0.04 \mathrm{~g} / \mathrm{L}$ ). These findings have further confirmed the superior of Aspergillus niger as the industrial production species for the citric acid production.

Even though there are many microbial sources available for citric acid production only a few are recognized for commercial production. Their vast diversity and specific range of action have attracted the attention of biotechnologists' worldwide. Presently, in India, little effort is being made to prepare citric acid using microorganisms. The best possible solution considering cost effectiveness may be the utilization of the indigenous and cheaper substances as like agricultural wastes and by products as substrate for the production of this valuable organic acid and then its further use in application like food and pharmaceutical industry. Therefore, the plan for future research investigations has been chalked out to produce citric acid using Aspergillus niger.

\section{Conflict of Interest}

There is no conflict in this study.

\section{Acknowledgements}

The facilities provided by Department of Microbiology, Ayya Nadar Janaki Ammal College, Sivakasi to carry out this study are gratefully acknowledged. The author also thanks UGC-SERO for providing financial support to carry out the project under Minor Research Project (MRP-5582/15).

\section{REFERENCES}

[1] Derivados, M. (1997). Selection of a strain of Aspergillus for the production of citric acid from pineapple waste in solid-state fermentation. W. J. Microbiol. Biotechnol., 14: 399-404.

[2] Vasanthabharathi, S.A., Munshi, M.K., Hossain, M.F., Huque, R., Rahman, M.M., Khatun, A., Islam M. and M.I. Khalil, (2013). Effect of biomass and sugar in citric acid production by Aspergillus niger using molasses and jackfruit as substrates. Am. J. Food Nutr., 1: 1-6.

[3] Papagianni, M. (2007). Advances in citric acid fermentation by Aspergillus niger: Biochemical aspects membrane transport and modeling. Biotechnol Adv., 25: 244-263.

[4] Yalcin, S.K., Bozdemir, M.T. and Ozbas, Z.Y. (2009). A comparative study on citric acid production kinetics of Yarrowia lipolytica strains in two different media. Ind. $J$. Islamic Academy Sci., 5: 101-106.

[5] Sauer, M., Porro, O., Matlanovich, D. and Branduardi, P. (2008). Microbial production of organic acids: Expanding the markets. Trends in Biotechnol., 26: 100-108.

[6] Nadeem, A., Syed, Q., Baig, S., Irfan, H., and Nadeem, M. (2010). Enhanced production of citric acid by Aspergillus niger M-101 using lower alcohols. Turk. J. Biochem., 35(1): 7-13.

[7] Soccol, C.R., Vandenberghe, L.P.S., Rodrigues, C. and Pandey., A. (2006). New perspectives for citric acid production and application. Food Technol. Biotechnol., 44(2): 141-149.

[8] Ali, S., Haq, I.U., Qadeer, M.A. and Iqbal, J. (2002). Production of citric acid by Aspergillus niger using cane molasses in a stirred fermentor. Elect. J. Biotech., 5: 258-271.

[9] Kim, J.W. (2004). Optimization citric acid production by Aspergillus niger NRRL 567 in various fermentation systems. Department of Biosystems Eng., 41: 220-225.

[10] Lofty, W.A., Ghanem, K.M. and El-Helow, E.R. (2007). Citric 
acid production by a novel Aspergillus niger isolate: Mutagenesis and cost reduction studies. Bioresour Technol., 98: 3464-3469.

[11] Pandey, A., Soccol, C.R., Rodriguez-Leon, J.A. and Nigam, P. (2001). Production of organic acids by solid-state fermentation. In: Solid-state fermentation in Biotechnology Fundamentals and Applications. Asiatech Publishers Inc., New Delhi, India., 4: 113-126.

[12] Nester, E.W., Anderson, D.G., Roberts, E.C, Nancy, N.P. and Martha, T.N. (1998). Microbiology, a human perspective. $1^{\text {st }}$ edition, WcB McGraw Hill, New York., 20: 307-312.

[13] Domsch, K.H., Grams, W. and Anderson, T.H. (1980). Compedium of soil fungi. Academic press, London., 1/2:859-865.

[14] Sampo, S., Bergero, R., Buffa, G. and Luppi-Mosca, A.M. (1997). Soil fungal communities in young and old Alnus viridis coenosis. Mycopathologia., 89: 837-845.

[15] Darouneh., E, Alavi-Vosoughi, A. Arjmand, Seifkordi, A. and Rajabi, R. (2009). Citric acid production: Surface culture versus submerged culture. Afr. Microbiol, Res., 3: 541-545.
[16] Makut, M.D. and Ade-lbijola, O.B. (2012). Citric acid producing fungi found in the soil environment of Keffi metropolis, Nasarawa state, Nigeria. Int. Res. J. Microbiol., 3(7): 240-245.

[17] Ali, S. (2004). Studies on the submerged fermentation of citric acid by Aspergillus niger in a stirred fermentor, Ph.D. Thesis. University of Punjab Lahore, Pakistan., 114-115.

[18] AOAC, (1995). Offical Methods of Analysis. $16^{\text {th }}$ Association of Official Analytical Chemists Arlington, VA, USA.

[19] Rohr, M., Kubicek, C.P., Kominek, J. (1983). Citric Acid. In: Biotechnology. Ed. Reed, G. and Rehm, H.J. Vol. 3, Verlag Chemie, Weinheim, Germany. pp. 419-454.

[20] Kirimura, K., Lee, S.P., Kawajima, I., Kawabe, S. and Usami, S. (2000). Improvement in citric acid production by haploidization of Aspergillus niger diploid strains. J. Ferment. Technol., 66: 375-382.

[21] Torres, N.V. (1994). Modeling approach to control of carbohydrate metabolism during citric acid accumulation in Aspergillus niger. Biotechnol. Bioeng., 44: 104-111. 